\title{
FACTORS TO ENHANCE ECOTOURIST'S ECOTOURISM LOYALTY, MODERATING EFFECT OF SOCIAL INFLUENCE AND PSYCHOLOGICAL OWNERSHIP
}

\author{
Sinh Duc Hoang; Hung Viet Vo, ZuzanaTučKová \\ Tomas Bata University in Zlín, Faculty of Management and Economics
}

\begin{abstract}
Purpose: This study aims to provide novel insights via a joint investigation of the moderating effect of social influence and psychological ownership on ecotourism loyalty. It further explores and makes significant contributions to the Expectation Confirmation Theory.

Design/methodology/approach: Using longitudinal survey data gathered from 156 respondents before and after their travels, this research assesses the moderating role of social influence and psychological ownership on two of the well-established relationships in ecotourism loyalty.

Findings: Results show that social influence and psychological ownership have a strong moderation effect on the relationship between ecotourism satisfaction and ecotourism loyalty.

Practical implications: This study has two specific practitioner contributions. First, the study findings emphasize the importance of expectation management from the perspective of expectation management. Managers should exercise caution when providing false information about the location. There are dangers in setting unrealistic expectations for both travel planning and tourism management. Social media is regarded as a powerful 'word-ofmouth' source that can be used to exert negative influence from dissatisfied customers. As a result, proper social media management is critical. Second, researchers point out that vacationers' cognitive-affective connection to a destination is critical, along with the intangibles mentioned earlier, as a sense of ownership, ambiance, and perception of the image of the place they have of the destination. When people want to identify with a destination, they feel ownership of it. The brand strategy needs to be embedded in the destination strategy to target different target tourism identity parameters, like image, style, and values. A destination's connectivity to people's values can be generated if the destination is viewed as a place that people identify with rather than a transient location.
\end{abstract}

Keywords: social influence, psychological ownership, ecotourism loyalty

JEL Classification: M31, Z32

\section{Introduction}

Ecotourism has become a vital activity in the lives of people who like engaging in adventures. Various factors affect ecotourism. Firstly, tourism loyalty involves psychological attachment between the tourists and their preferred destination (Oppermann, 2000). This form of psychological commitment is usually developed when the tourists leave the tourist destination with a positive experience. Various factors determine whether the tourist's experience is bad or good. Tourists' experience is a broad field that ranges from their host's behavior and other interactive features of their destination. Most of the experience of tourists is determined by four

https://doi.org/10.11118/978-80-7509-820-7-0388 
aspects: entertainment, education, escapist, and aesthetic (Ali et al., 2014). Entertainment is mainly the ability of their destination to entertain the tourist. It involves how their hosts treated them and how the destination features fulfilled their emotional appeal.

Secondly, psychological ownership is a form of attraction that creates a sense of ownership in the tourist with the features of the destination (Kumar \& Nayak, 2019). When tourists develop such a form of psychological possession of the features of the destination, they will create a positive attitude towards such features. Psychological ownership for particular features and destinations develops when these features and destinations possess characteristics that conform to the preferences of the tourists. Different tourists have different priorities that they consider when choosing a tourist destination. When the chosen destinations meet the likes of the tourists, they feel connected to such destinations because they will enjoy the scenery and have a positive attitude towards such areas, thus having a positive experience which is a crucial component in the development of psychological ownership.

Lastly, social influence involves shaping the way tourists believe and view a particular destination (Turner, 1991). Various factors determine the perception of people toward a specific destination and its features. Some of these factors include culture, nationality, family, and relatives, among other factors (Brayley et al., 1990). With the emergence of social media, most social influence nowadays tends to come from digital platforms such as Facebook and other social media sites (Bizirgianni \& Dionysopoulou, 2013). Social media has enabled people to view different features and destinations of different places before their visit. These sites act as advertisement platforms that tend to market the features of their respective destinations to attract people to such places. Most of the adverts are usually based on the quality of hospitality of the area because they understand that most tourists tend to judge a specific destination by the quality of their services. This research investigates the factors that affect ecotourism loyalty, moderating social influence, and psychological ownership in the tourism industry.

\section{Literature review}

Destination image remains a critical aspect in marketing a tourist destination (Echtner, \& Ritchie, 1991). For a tourist destination to attract a significant number of tourists, it must have a positive image. There are various ways that a destination acquires its image. One of the main ways is by fulfilling the expectations of the tourists (Santos, 1998). Before visiting a particular destination, most tourists usually conduct pre-visit research. This research is essential in informing the tourists of the kind of features they expect to find at the tourist attraction (Frías et al., 2012). There are several ways the tourist employs to acquire information about a specific place (de la Hoz-Correa \& Muñoz-Leiva, 2019). One of the main ways of obtaining information about a particular destination is through social media (Narangajavana et al., 2017). Social media platforms have various features that enable people to connect with friends with people they have never met physically (Lange-Faria \& Elliot 2012). For instance, Facebook has a section for friends to allow users to find friends from 
other parts of the world and connect with them. Through these friends, people can make features that appear to be appealing to the tourist to create expectations within the tourist.

The experience tourists get from their trip to a particular destination is determined by various factors that apply during the entire trip (Cutler \& Carmichael, 2010). Some of these factors include the hospitality that these tourists are treated to within their destinations (Graefe \& Vaske, 1987). Hospitality includes accommodation, social involvement in the events taking place in their destination, other aspects such as culture and infrastructure of the destination, which play an important role in determining the kind of experience tourists get from their destination (Pizam \& Reichel, 1978). When these features conform to the expectations of the tourists, they will have to create a positive experience. Experience is a psychological aspect that is fulfilled when the tourists emotionally connect themselves with the events they engage in (Larsen, 2007). such connections generate memories that make up the positive experience. When tourist gets a positive experience, they develop a positive destination image of their destination. This comes from fulfilling their expectations and their satisfaction from the events they engage in their trip (Larsen, 2006). Tourists tend to record their experiences throughout their trips. They use such recordings as a reminder of the memories they made in a particular destination.

Satisfaction can be defined as the ability of service providers to meet the expectations and the needs of their customers. A product or service also can meet the needs and the expectations that the customers have towards that particular product or service. This is the same case with the tourism industry. Various reasons make tourists visit a particular destination. These reasons create expectations such that when tourists visit a particular destination, they have expectations that such destinations should meet. When their expectations are met through the experience they get from their trips, and they get satisfied (Neal \& Gursoy, 2008). A positive image of a particular destination plays a more significant role in meeting the tourist's expectations. This case enables tourists to get satisfied with the kind of treatment that they get from such destinations.

In the service sector, customer loyalty is vital. The services customers get from the service provider play an essential role in determining whether the customer will revisit the service provider. Customer loyalty is generated from the positive experience that the customers get from the service provider. This is the same case with the tourism industry. The kind of experience that the tourists develop from their various destinations determines whether they will revisit the same destination in the future or they will recommend it to other tourists. Positive experiences tend to create positive memories that connect the tourists to their various destinations. Loyalty can be defined as a deeply held commitment to re-purchase or re-patronize preferred goods or services consistently in the future, which results in repeated sales of the brand or the same brand set buying despite, despite situational influences and marketing efforts that have the potential of causing customers to change behavior (Oliver, 1999).

Facebook and other sites have enabled people to share pictures and videos of various destinations and their features. They can also share their experiences about 
various destinations and the relevant information essential in helping potential tourists identify the different destinations that conform to their preferences. Social influence is also determined by interactions with family members and relatives who have had experience with a particular destination. According to psychologists, social influence interactions with people who have close ties with each other tend to influence their beliefs and their emotions concerning a specific object. People tend to think in the same direction as those people they spend time with. In this case, the opinion of family members plays an essential role in influencing the thoughts of a potential tourist towards a particular destination.

Psychological ownership is a feeling of possessiveness towards a particular object, place, organization, or person they do not legally own. Several factors determine psychological ownership. Some of them include the experience that individual shares with the particular object and the satisfaction that the consumers of a particular product get from using a particular product or service. In tourism, psychological ownership is portrayed when tourists develop a sense of ownership towards a particular tourist destination. This feeling of possessiveness is influenced by the features that tourist tourists find in their various destinations. Tourists have various preferences that they tend to look for when looking for a destination for their trip. When they find a tourist destination that matches their preferences, they tend to develop ownership of such places. A positive destination image creates expectations that the tourist looks forward to fulfilling the destination's expectations. Such expectations are generated because the destination image contains features that meet the tourists' preferences.

H1: Tourist expectation has a positive effect on destination image.

H2: Ecotourist experience has a positive effect on destination image.

H3: Destination image has a positive effect on ecotourism satisfaction.

H4: Destination image has a positive effect on ecotourism loyalty.

H5: Ecotourism satisfaction has a positive effect on ecotourism loyalty.

H6: Social influence moderates the effect between tourist expectation and destination image.

H7: Social influence moderates the effect between destination image and ecotourism satisfaction.

H8: Psychological ownership moderates the effect between tourist expectation and destination image.

H9: Psychological ownership moderate the effect between destination image and ecotourism satisfaction. 


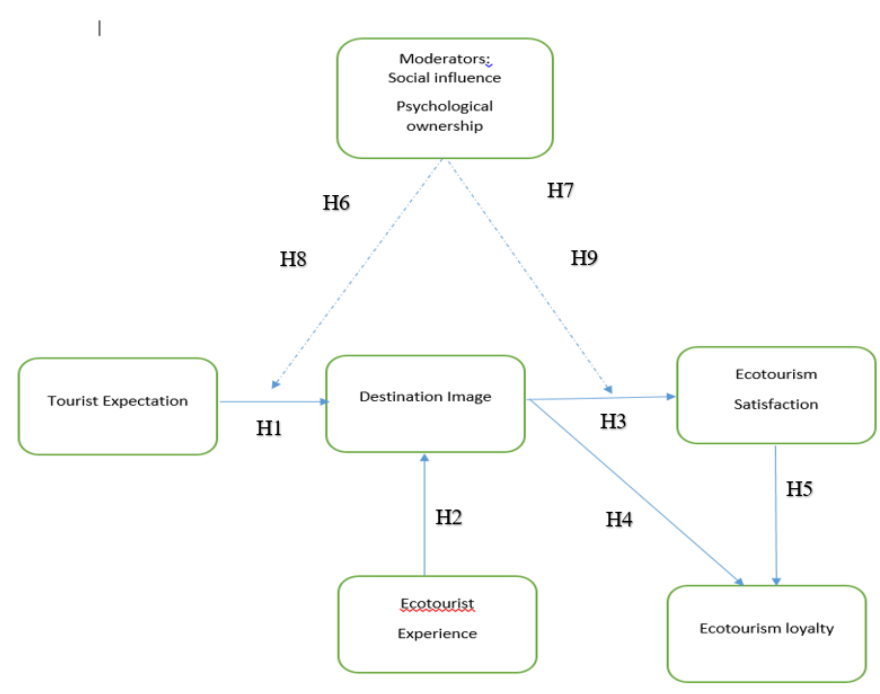

Figure 1. Conceptual framework

Source: own research

\section{Methodology}

The participants were a mixture of both locals and foreigners who mainly were adults. Gender equality was considered with an equal number of people belonging to each gender. The subgroups also consisted of an equal number of men and women. During the research, each group had to choose its own destination. All the participants were non-locals, so that the research can be fully considered to be ecotourism research.

The primary method of data collection in used in the survey was longitudinal method. This method involves observing a certain trend under research for a period to establish the connection between the variables. The research took at approximately one month and involved tourists who were both familiar and unfamiliar with their respective destinations. Those who were familiar with the tourist destination were primarily under the psychological ownership segment while those who were unfamiliar with the destination were under the social influence segment. The management of the destination designed social media posts about their tourist center and posted them on different platforms. The posts were designed in a more attractive form than the most of the other posts featuring the best sceneries and other points of attraction. The participants were then exposed to the different posts of various destinations. Data was then recorded according to the kind of posts that were chosen as the preferred destinations. There are those who chose their destinations because they were there before, and they liked the experience and such destinations had features that they felt connected emotionally. On the other hand, there are those who chose their destinations for the time, and they were influenced by the beautiful sceneries and the positive image of the destinations as presented in 
the posts and from the comments that they had received from the social media users who had been to such destinations before. Lastly, those who belonged to the psychological ownership were familiar with specific features such as islands, beaches, waterfronts, and other natural elements. Dividing segments into such categories was crucial in ensuring that the correct data was collected remains within the context of the research topic.

\section{Results}

The theoretical model was analyzed through partial least square methodology drawn upon structural equation modeling via the SMART-PLS software. The authors decided to deploy PLS-SEM over other co-variance-based data modeling techniques was attributed to the small sample size and the non-normality of data (Goodhue, Lewis and Thompson, 2012; Hair et al., 2017). PLS-SEM offers an explanation of causal relationships among multiple variables without strict assumptions and pre-conditions (Hair et al., 2017), which makes PLS-SEM the inferential tool of choice. The composite reliability (CR) and average variance extracted (AVE) were tested for convergent validity of the model, especially CR and AVE values had to exceed the recommended value of 0.7 and 0.5 , respectively, which can indicate the latent constructs (Hair et al., 2013). Tables 1 shows the high value of all item loadings from above 0.7 . Therefore, the valid values for CR and AVE were retained significantly.

Table 1: Construct reliability and validity

\begin{tabular}{|c|c|c|c|c|c|c|}
\hline Variables & Items & $\begin{array}{c}\text { Factor } \\
\text { loadings }\end{array}$ & $\begin{array}{c}\text { Cronbach's } \\
\text { Alpha }\end{array}$ & $\overline{A V E}$ & CR & rho_A \\
\hline \multirow[t]{3}{*}{$\mathrm{TE}$} & TE1 & 0.797 & \multirow[t]{3}{*}{0.718} & \multirow[t]{3}{*}{0.637} & \multirow[t]{3}{*}{0.841} & \multirow[t]{3}{*}{0.721} \\
\hline & TE2 & 0.792 & & & & \\
\hline & TE3 & 0.806 & & & & \\
\hline \multirow[t]{4}{*}{ DI } & DI1 & 0.883 & \multirow[t]{4}{*}{0.858} & \multirow[t]{4}{*}{0.699} & \multirow[t]{4}{*}{0.903} & \multirow[t]{4}{*}{0.878} \\
\hline & DI2 & 0.786 & & & & \\
\hline & DI3 & 0.84 & & & & \\
\hline & DI4 & 0.832 & & & & \\
\hline \multirow[t]{3}{*}{ ES } & ES1 & 0.997 & \multirow[t]{3}{*}{0.995} & \multirow[t]{3}{*}{0.989} & \multirow[t]{3}{*}{0.996} & \multirow[t]{3}{*}{0.996} \\
\hline & ES2 & 0.997 & & & & \\
\hline & ES3 & 0.991 & & & & \\
\hline \multirow[t]{4}{*}{ EE } & EE1 & 0.891 & \multirow[t]{4}{*}{0.867} & \multirow[t]{4}{*}{0.718} & \multirow[t]{4}{*}{0.91} & \multirow[t]{4}{*}{0.872} \\
\hline & EE2 & 0.904 & & & & \\
\hline & EE3 & 0.834 & & & & \\
\hline & EE4 & 0.75 & & & & \\
\hline EL & EL1 & 0.942 & 0.945 & 0.857 & 0.96 & 0.953 \\
\hline
\end{tabular}




\begin{tabular}{|c|c|c|c|c|c|c|}
\hline Variables & Items & $\begin{array}{c}\text { Factor } \\
\text { loadings }\end{array}$ & $\begin{array}{c}\text { Cronbach's } \\
\text { Alpha }\end{array}$ & AVE & CR & rho_A \\
\hline & EL2 & 0.939 & & & & \\
\hline & EL3 & 0.915 & & & & \\
\hline \multirow[t]{3}{*}{ SI } & SI1 & 0.942 & \multirow[t]{3}{*}{0.935} & \multirow[t]{3}{*}{0.757} & \multirow[t]{3}{*}{0.86} & \multirow[t]{3}{*}{0.923} \\
\hline & SI2 & 0.939 & & & & \\
\hline & SI3 & 0.915 & & & & \\
\hline \multirow[t]{3}{*}{ PO } & PO1 & 0.821 & \multirow[t]{3}{*}{0.837} & \multirow[t]{3}{*}{0.728} & \multirow[t]{3}{*}{0.791} & \multirow[t]{3}{*}{0.787} \\
\hline & $\mathrm{PO} 2$ & 0.914 & & & & \\
\hline & PO3 & 0.925 & & & & \\
\hline
\end{tabular}

\section{Discussion and implication}

The results suggested that social media plays a major role in influencing the potential tourists to choose the king of destination that they want. Social influence also comes from tother social media users who give various comments about a particular destination according to the kind of experience that they had with that particular destination. tourists choose their destinations according to the destination image. A positive destination image leads to the creation of expectations. Those who responded to the questions about destination image said that positive destination image led to creating expectations that would make them aware of the kind of experience they would expect in their respective destinations (Picazo \& Moreno-Gil, 2019). When these expectations are met, they lead to positive experience. A positive experience leads to ecotourism satisfaction. When the tourist is satisfied, they develop psychological ownership towards the destination. from the study, psychological ownership is determined by various factors. They include post-trip experience, social influence from social media, and family and friends, and satisfaction (Zare, 2019). Psychological ownership leads to ecotourism loyalty. This is because tourist tend to develop connection with certain features in the destination that created a positive experience. Therefore, they will tend to revisit such destinations often to fulfil their emotional connection with the specific features. They will also tend to recommend such destinations to other potential tourists (Lee \& Kim, 2020).

However, there are circumstances where the destination managers create a false image of their destinations in order to attract the attention of potential tourists. Such false information creates expectations in the mind of the tourist. During the actual visit, the tourist destination may fail to fulfil such expectations. This in turn leads to a bad experience which translates to dissatisfaction, and they may develop a negative image about such destinations. Negative destination image may influence other potential tourists negatively and they may shun such destinations. On the other hand, when the information about a particular destination is factual, genuine expectations are created and such expectations are likely to be fulfilled during the actual trip. As a result, the tourists generate a feeling of ownership towards such destinations and may influence others positively about such destinations. 


\section{Limitation and future research}

Several limitations were encountered during the research. Firstly, the study was mainly limited to Vietnam; therefore, its generalization was limited too. Future research should take place in other destinations in other countries. Secondly, the study involved the post-trip responses, which may have provided limited data. Future research should focus on different occasions before the trip, during the trip, and after the trip. The study should start at the initial stages of the trip. Thirdly, the study was mainly limited to ecotourism. Future research should focus on other forms of tourism as well.

\section{Acknowledgment.}

The authors would like to thank the Internal Grant Agency of FaME for providing financial support to carry out this research. The funding was extended through UTB No. IGA/FaME/005/2020.

\section{References}

1. Ali, F., Hussain, K., \& Ragavan, N. A. (2014). Memorable customer experience: Examining the effects of customers experience on memories and loyalty in Malaysian resort hotels. Procedia-Social and Behavioral $\quad$ Sciences, 144, 273-279. https://doi.org/10.1016/j.sbspro.2014.07.296

2. Bizirgianni, I., \& Dionysopoulou, P. (2013). The influence of tourist trends of youth tourism through social media (SM) \& information and communication technologies (ICTs). ProcediaSocial and Behavioral Sciences, 73, 652-660. https://doi.org/10.1016/j.sbspro.2013.02.102

3. Brayley, R., Var, T., \& Sheldon, P. J. (1990). Perceived influence of tourism on Social Issues. Annals of Tourism Research, 17(2), 285-289. https://doi.org/10.1016/01607383(90)90089-A

4. Cutler, S. Q., \& Carmichael, B. A. (2010). The dimensions of the tourist experience. In The tourism and leisure experience (pp. 3-26). Channel View Publications.

5. de la Hoz-Correa, A., \& Muñoz-Leiva, F. (2019). The role of information sources and image on the intention to visit a medical tourism destination: a cross-cultural analysis. Journal of Travel \& Tourism Marketing, 36(2), 204-219.

6. Echtner, C. M., \& Ritchie, J. B. (1991). The meaning and measurement of destination image. Journal of tourism studies, 2(2), 2-12.

7. Frías, D. M., Rodríguez, M. A., Alberto Castañeda, J., Sabiote, C. M., \& Buhalis, D. (2012). The formation of a tourist destination's image via information sources: The moderating effect of culture. International Journal of Tourism Research, 14(5), 437-450.

8. Goodhue, D.L., Lewis, W., \& Thomson, R. (2012). Does PLS Have Advantage for Small sample size or Non-normal Data? MIS Quarterly, 36(3), 981-1001. https://doi.org/10.2307/41703490

9. Graefe, A. R., \& Vaske, J. J. (1987). A framework for managing quality in the tourist experience. Annals of tourism research, 14(3), 390-404.

10. Hair, J.F., Hult, G, T.M., Ringle, C.M., and Sarstedt, M. (2013). A Premier on Partial Least Squares Structural Equation Modelling (PLS-SEM). US: Sage.

11. Hair, J.F., Hult, G, T.M., Ringle, C.M., and Sarstedt, M. (2017). A Premier on Partial Least Squares Structural Equation Modelling (PLS-SEM). US: Sage. 
12. Kumar, J., \& Nayak, J. K. (2019). Exploring destination psychological ownership among tourists: Antecedents and outcomes. Journal of Hospitality and Tourism Management, 39, 3039.

13. Lange-Faria, W., \& Elliot, S. (2012). Understanding the role of social media in destination marketing. Tourism, 7(1).

14. Larsen, S. (2006). The Psychology of the Tourist Experience Expectations, Events, and Memories. CAUTHE 2006: To the City and Beyond, 1499.

15. Larsen, S. (2007). Aspects of a psychology of the tourist experience. Scandinavian Journal of Hospitality and Tourism, 7(1), 7-18.

16. Lee, S., \& Kim, D. Y. (2020). The BRAND tourism effect on loyal customer experiences in a luxury hotel: The moderating role of psychological ownership. Tourism Management Perspectives, 35, 100725.

17. Narangajavana, Y., Fiol, L. J. C., Tena, M. Á. M., Artola, R. M. R., \& García, J. S. (2017) The influence of social media in creating expectations. An empirical study for a tourist destination. Annals of Tourism 60-70. https://doi.org/10.1016/j.annals.2017.05.002

18. Neal, J. D., \& Gursoy, D. (2008). A multifaceted analysis of tourism satisfaction. Journal of Travel Research, 47(1), 53-62. https://doi.org/10.1177/0047287507312434

19. Oliver, R. L. (1999). Whence consumer loyalty? Journal of marketing, 63(4_suppl1), 33-44.

20. Oppermann, M. (2000). Tourism destination loyalty. Journal of travel research, 39(1), 78-84.

21. Picazo, P., \& Moreno-Gil, S. (2019). Analysis of the projected image of tourism destinations on photographs: a literature review to prepare for the future. Journal of Vacation Marketing, 25(1), 3-24. https://doi.org/10.1177/1356766717736350

22. Pizam, A., Neumann, Y., \& Reichel, A. (1978). Dimensions of tourist satisfaction with a destination area. Annals of Tourism Research, 5(3), 314-322. https://doi.org/10.1016/01607383(78)90115-9

23. Turner, J. C. (1991). Social influence. Thomson Brooks/Cole Publishing Co.

24. Zare, S. (2019). Recall and post-trip evaluation of tourist destinations: the effects of travel order (Doctoral dissertation, James Cook University). 